\title{
Development the concept of using XML- schemas and requirements for them for the transfer and storage of information, documents and materials included in the information model of capital construction objects
}

\author{
Pavel Chelyshkov ${ }^{1 *}$, Sergey Volkov ${ }^{2}$, Evgeny Babushkin ${ }^{1}$ and Diana Zueva ${ }^{1}$ \\ ${ }^{1}$ Moscow State University of Civil Engineering, Moscow 129337, Russia \\ ${ }^{2}$ Centre of Expertise for Major Construction Projects, Private Enterprise of the Rosatom State Atomic \\ Energy Corporation, Moscow 119180, Russia
}

\begin{abstract}
The lack of a unified structure of the information model at different stages of the life cycle for different types of capital construction objects and the lack of requirements for the composition and content of the information model causes the problem of transferring the information model of the capital construction object from one stage to another in order to exchange and analyze data on objects throughout the entire life cycle. cycle, which will allow to simultaneously take into account technological, financial, technical parameters and the time factor, maintaining the data in an up-to-date and complete state at any time for all participants in the investment and construction process, including management companies, operating, repair, construction, subcontracting, design and research organizations, supervisory and control bodies.

The goal of this article is to develop a concept for using XML schemas for transferring from one stage of the life cycle to another and storing information, documents and materials included in the information model of capital construction objects.
\end{abstract}

\section{Introduction}

To the main problem of the lack of a unified structure of the information model at different stages of the life cycle for different types of capital construction objects and the absence of requirements for the composition and content of the information model, it is also worth adding the problems that logically arise from it:

1. Lack of mechanisms for machine verification (verification) of data transmitted in the form of an information model of the capital construction object or certain parts of the information model between different systems (for example, from the customer to the expertise, from the contractor to the GISOGD or other state information systems).

\footnotetext{
${ }^{*}$ Corresponding author: chelyshkovpd@mgsu.ru
} 
2. Lack of a modern methodological basis for the formation of the structure of the information model at different stages of the life cycle for different types of capital construction projects.

The goal of this article is to develop a concept for using XML schemas for transferring from one stage of the life cycle to another and storing information, documents and materials included in the information model of capital construction objects.

As part of solving this problem, the authors carried out:

1. Development of the concept of using XML-schemas for the transfer and storage of information, documents and materials included in the information model of capital construction objects at all stages of the life cycle of capital construction objects;

2. Development of methodological approaches to the use of standard models for the formation of the structure of the information model at different stages of the life cycle for different types of capital construction objects;

3. Development of requirements for XML-schemas that completely define the structure and composition of the information model both at the top (root) level, which determines the composition of documents included in the information model, and at the lower levels - the components of the information model, taking into account the stages: surveys, implementation of architectural and construction design. For the stages of construction, reconstruction, overhaul, operation and (or) demolition of a capital construction facility, framework requirements have been developed.

The obtained research results are presented in the form:

1. Concepts for the use of XML schemas for the transfer and storage of information, documents and materials included in the information model of capital construction objects in the full life cycle.

2. Methodological approaches to the use of standard models for the formation of the structure of the information model at different stages of the life cycle for different types of capital construction projects.

3. Requirements for XML schemas, which completely define the structure and composition of the information model.

\section{Materials and methods}

\subsection{The concept of using XML schemas for the transfer and storage of information, documents and materials included in the information model of capital construction objects in the full life cycle}

This section of the article provides a consolidated list of XML schemes necessary and sufficient to support the stages of the life cycle of a capital construction object in terms of interaction with the State Information System for the Support of Urban Development.

Table 1. List of XML schemas that support the life cycle of a capital construction object

\begin{tabular}{|l|l|l|}
\hline \multicolumn{1}{|c|}{$\begin{array}{c}\text { Life } \\
\text { cyclestagename }\end{array}$} & $\begin{array}{c}\text { The level of elaboration } \\
\text { of the digital } \\
\text { information model }\end{array}$ & \multicolumn{1}{c|}{ XML-schemas } \\
\hline Atallstages & - & Core XML-schema \\
\hline \multirow{2}{*}{$\begin{array}{l}\text { Engineering } \\
\text { survey }\end{array}$} & $\begin{array}{l}\text { Engineering survey } \\
\text { model }\end{array}$ & $\begin{array}{l}\text { XML-schema of information model } \\
\text { of engineering survey }\end{array}$ \\
\cline { 3 - 3 } & $\begin{array}{l}\text { XML-schema for the conclusion of } \\
\text { the examination of engineering } \\
\text { survey results }\end{array}$ \\
\hline
\end{tabular}




\begin{tabular}{|c|c|c|}
\hline \multirow{4}{*}{$\begin{array}{l}\text { Investment } \\
\text { justification }\end{array}$} & \multirow{4}{*}{ Conceptual model } & $\begin{array}{l}\text { Conceptual Model XML Schema } \\
\text { for Buildings and Structures }\end{array}$ \\
\hline & & $\begin{array}{l}\text { Conceptual Model XML Schema } \\
\text { for Line Features }\end{array}$ \\
\hline & & $\begin{array}{l}\text { Optional Conceptual Technology } \\
\text { Model XML Schemas }\end{array}$ \\
\hline & & $\begin{array}{l}\text { Investment justification } \\
\text { Examination Report XML Schema }\end{array}$ \\
\hline \multirow{4}{*}{$\begin{array}{l}\text { Architectural and } \\
\text { construction } \\
\text { design }\end{array}$} & \multirow{4}{*}{ Design model } & $\begin{array}{l}\text { XML schema of the design model } \\
\text { for buildings and structures }\end{array}$ \\
\hline & & $\begin{array}{l}\text { XML schema of the design model } \\
\text { for line features }\end{array}$ \\
\hline & & $\begin{array}{l}\text { Optional XML schemas for design } \\
\text { process models }\end{array}$ \\
\hline & & $\begin{array}{l}\text { XML-schema of the project } \\
\text { expertise conclusion }\end{array}$ \\
\hline \multirow{10}{*}{$\begin{array}{l}\text { Construction, } \\
\text { Reconstruction, } \\
\text { Overhaul }\end{array}$} & \multirow{5}{*}{ Construction model } & $\begin{array}{l}\text { Constructionmodel XML schema } \\
\text { for buildings and structures } \\
\text { (Construction and Renovation) }\end{array}$ \\
\hline & & $\begin{array}{l}\text { Construction Model XML Schema } \\
\text { for Linear Objects (Construction } \\
\text { and Renovation) }\end{array}$ \\
\hline & & $\begin{array}{l}\text { ConstructionModel XML Schema } \\
\text { (Overhaul) }\end{array}$ \\
\hline & & $\begin{array}{l}\text { ConstructionModel XML Schema } \\
\text { for Linear Features (Overhaul) }\end{array}$ \\
\hline & & $\begin{array}{l}\text { Optional XML schemas of building } \\
\text { technology models }\end{array}$ \\
\hline & \multirow{5}{*}{ Executive model } & $\begin{array}{l}\text { XML Schema of the Executive } \\
\text { Model for Buildings and Structures } \\
\text { (Construction and Renovation) }\end{array}$ \\
\hline & & $\begin{array}{l}\text { XML schema of the executive } \\
\text { model for linear objects } \\
\text { (Construction and Reconstruction) }\end{array}$ \\
\hline & & $\begin{array}{l}\text { Buildings and Structures Executive } \\
\text { Model XML Schema (Overhaul) } \\
\end{array}$ \\
\hline & & $\begin{array}{l}\text { Executive XML Schema for Linear } \\
\text { Objects (Overhaul) }\end{array}$ \\
\hline & & $\begin{array}{l}\text { Optional XML schemas of } \\
\text { executive technology models }\end{array}$ \\
\hline \multirow{3}{*}{ Exploitation } & \multirow{3}{*}{ Operational model } & $\begin{array}{l}\text { XML schema of the operational } \\
\text { model for buildings and structures }\end{array}$ \\
\hline & & $\begin{array}{l}\text { Operational Model XML Schema } \\
\text { for Line Features }\end{array}$ \\
\hline & & $\begin{array}{l}\text { Optional XML schemas of } \\
\text { operational process models }\end{array}$ \\
\hline $\begin{array}{l}\text { Demolition and } \\
\text { disposal }\end{array}$ & $\begin{array}{l}\text { Demolition and disposal } \\
\text { model }\end{array}$ & $\begin{array}{l}\text { Demolition and Recycling Model } \\
\text { XML Schema for Buildings and } \\
\text { Structures }\end{array}$ \\
\hline
\end{tabular}




\begin{tabular}{|l|l|l|}
\hline & \multicolumn{1}{|c|}{$\begin{array}{l}\text { Demolition and disposal model } \\
\text { XML schema for linear objects }\end{array}$} \\
& $\begin{array}{l}\text { Optional XML schemas of } \\
\text { demolition and disposal process } \\
\text { models }\end{array}$ \\
\hline
\end{tabular}

This annotated list of XML schemas provides support for the processes of interaction with state information systems throughout the entire life cycle of a capital construction object.

\subsection{Methodological approaches to the use of standard models for the formation of the structure of the information model at different stages of the life cycle for different types of capital construction objects}

Section 1 of the article provided an exhaustive list of XML schemes that support the processes of interaction with state information systems throughout the entire life cycle of a capital construction object. Let us further consider the matrices of scenarios for the use of XML schema data in coordinates: participants, stages of the life cycle.

\subsubsection{Stage "Engineering survey".}

The main participants in the "Engineering Survey" life cycle stage are:

- the developer, technical customer, the person responsible for the operation of the capital construction facility (hereinafter referred to as the customer);

- an individual entrepreneur or a legal entity performing work under a contract for the performance of engineering surveys concluded with a developer, technical customer, a person responsible for the operation of a capital construction facility (hereinafter referred to as the contractor);

- authorized government bodies of executive power, subordinate to these bodies, state (budgetary or autonomous) institutions, state (budgetary or autonomous) institution subordinate to the Ministry of Construction, Housing and Utilities of the Russian Federation, State Atomic Energy Corporation Rosatom (hereinafter - organizations for conducting state expertise).

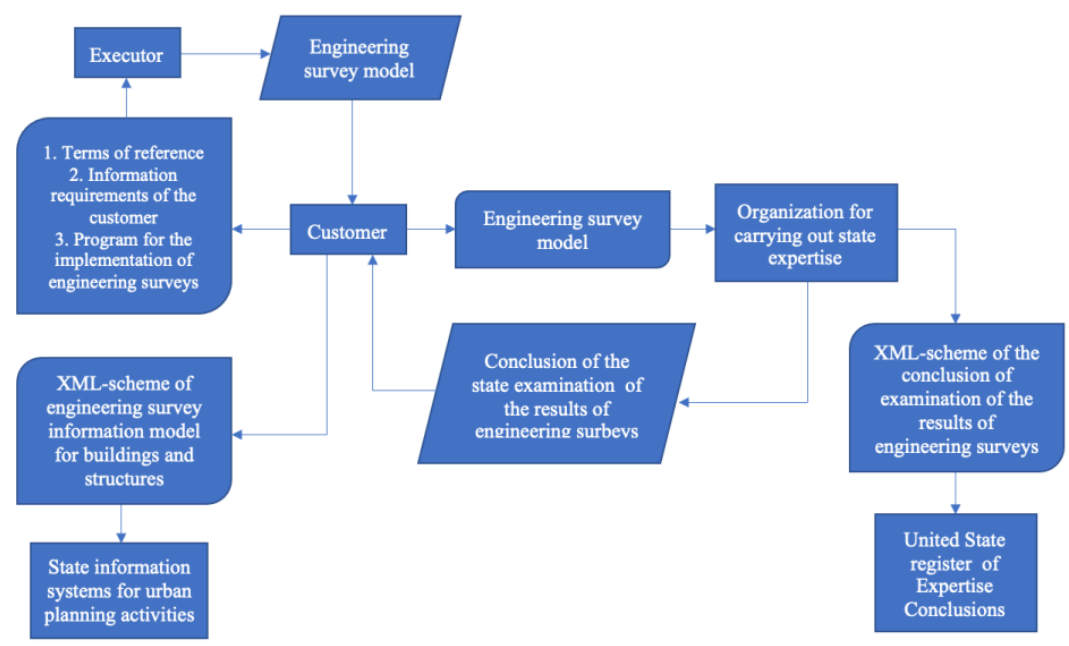

Fig. 1. Scheme of a scenario for using xml-schemes for the stage "Engineering Survey". 


\subsubsection{Stage "Justification of investments".}

The main participants in the Investment Rationale life cycle stage are:

- a developer, technical customer, a person providing or carrying out the preparation of the investment feasibility study (hereinafter referred to as the customer);

- an individual entrepreneur or a legal entity performing work on a contract concluded with a developer, technical customer, a person providing or preparing an investment feasibility study, an investment feasibility study agreement (hereinafter referred to as the executor);

- authorized government bodies of executive power, subordinate to these bodies, state (budgetary or autonomous) institutions, state (budgetary or autonomous) institution subordinate to the Ministry of Construction, Housing and Utilities of the Russian Federation, State Atomic Energy Corporation Rosatom (hereinafter - organizations for conducting state expertise).

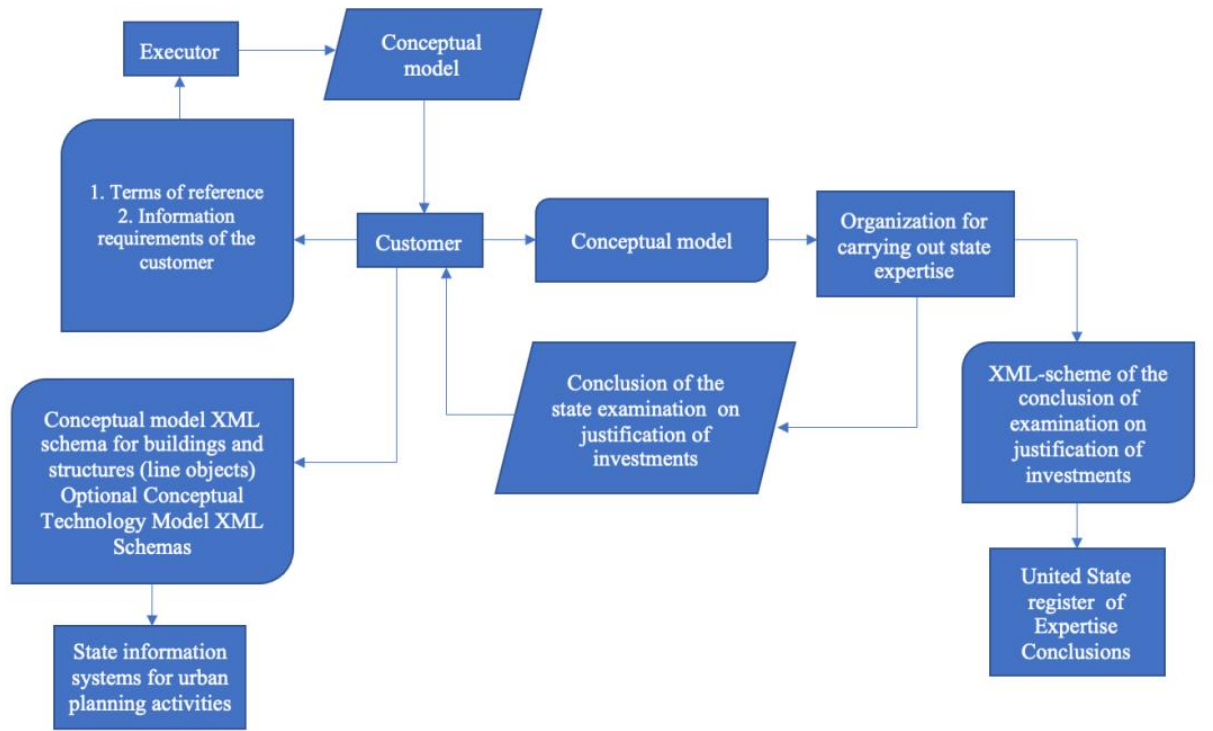

Fig. 2. Scheme of the scenario of XML-schemes application for the stage "Justification of investments".

\subsubsection{Stage "Architectural and construction design".}

The main participants in the life cycle stage "Architectural and construction design" are:

- the developer, technical customer, the person responsible for the operation of the capital construction facility (hereinafter referred to as the customer);

- an individual entrepreneur or a legal entity performing work on an agreement concluded with a developer, technical customer, a person responsible for the operation of a capital construction object on the preparation of project documentation in the form of an information model of a capital construction object, on amendments to such documentation (hereinafter referred to as the executor);

- authorized to conduct state expertise executive bodies, subordinate to these bodies, state (budgetary or autonomous) institutions, state (budgetary or autonomous) institution subordinate to the Ministry of Construction and Housing and Communal Services of the 
Russian Federation, State Atomic Energy Corporation "Rosatom" (hereinafter organizations for conducting state expertise).

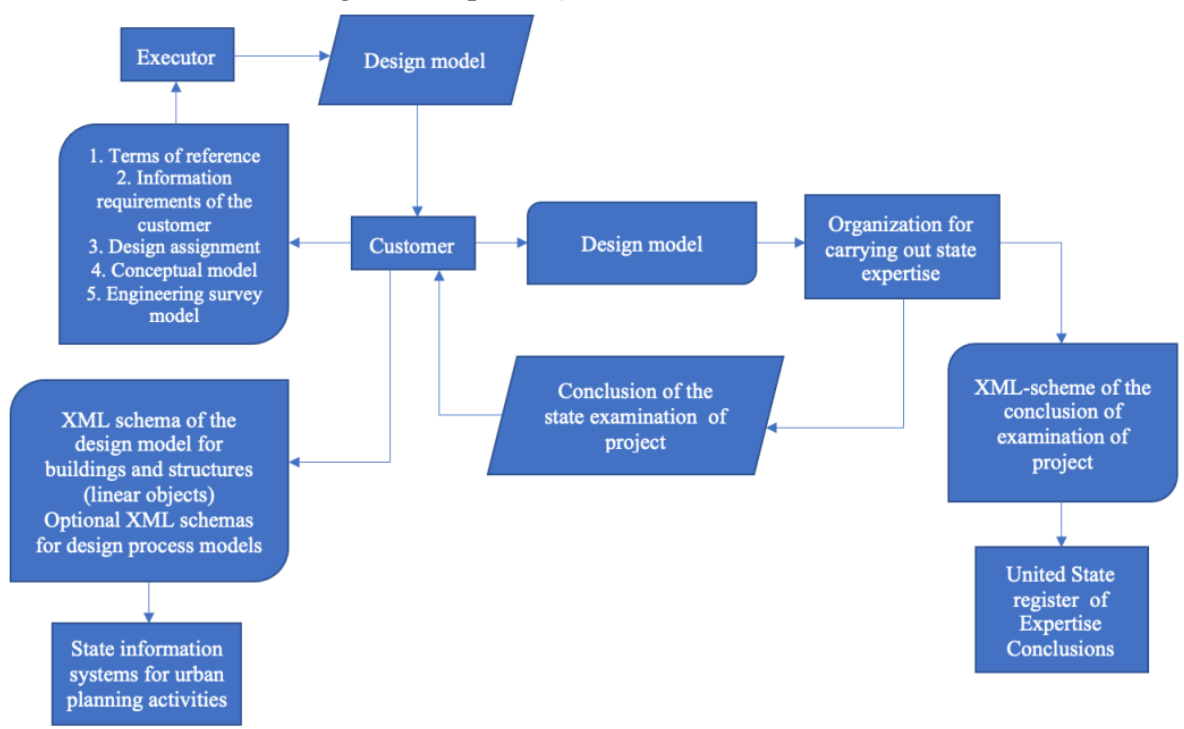

Fig. 3. Scheme of a scenario for using XML-schemes for the stage "Architectural and construction design".

\subsubsection{Stage "Construction, reconstruction, overhaul".}

The main participants in the life cycle stage "Construction, reconstruction, overhaul" are:

- the developer, technical customer, the person responsible for the operation of the capital construction facility (hereinafter referred to as the customer);

- an individual entrepreneur or a legal entity performing work on a contract concluded with a developer, technical customer, a person responsible for the operation of a capital construction object, a contract for construction, reconstruction, overhaul of a capital construction object (hereinafter referred to as the executor);

- an individual entrepreneur or a legal entity performing work on a construction control agreement concluded with a developer, technical customer, a person responsible for the operation of a capital construction facility (hereinafter referred to as a contractor (construction control));

- an individual entrepreneur or a legal entity performing work under the contract of designer supervision concluded with the developer, technical customer, person responsible for the operation of the capital construction object (hereinafter referred to as the executor (designer's supervision));

- the body of state construction supervision. 


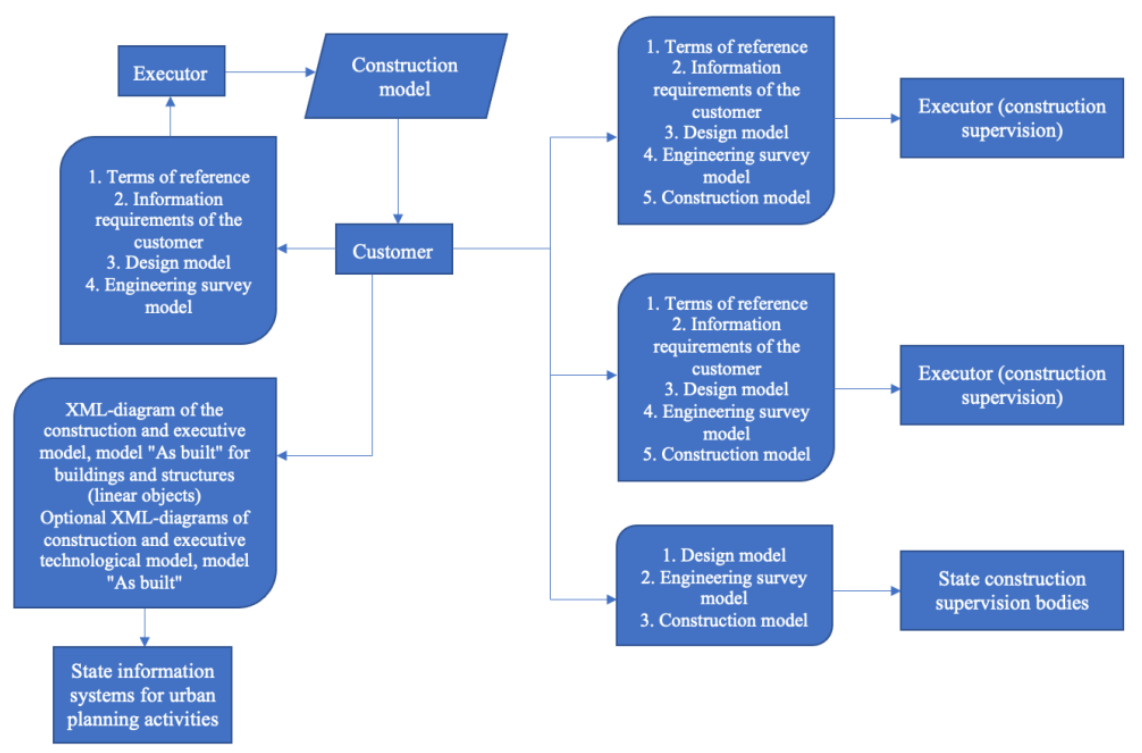

Fig. 4. Scheme of the scenario of using XML-schemes for the stage "Construction, reconstruction, overhaul".

\subsubsection{Stage "Operation".}

The main participants in the "Operation" life cycle stage are:

- the developer, technical customer, the person responsible for the operation of the capital construction facility (hereinafter - the operating organization);

- an individual entrepreneur or a legal entity performing work on a contract concluded with a developer, technical customer, a person responsible for the operation of a capital construction facility for the implementation of routine repairs of capital construction facilities, other contracts providing for the formation and maintenance of an information model by including in such a model interrelated information, documents, materials or their changes, in accordance with the composition of information, documents, materials included in the information model of a capital construction object, the requirements for electronic document formats established by the Government of the Russian Federation (hereinafter referred to as the executor).

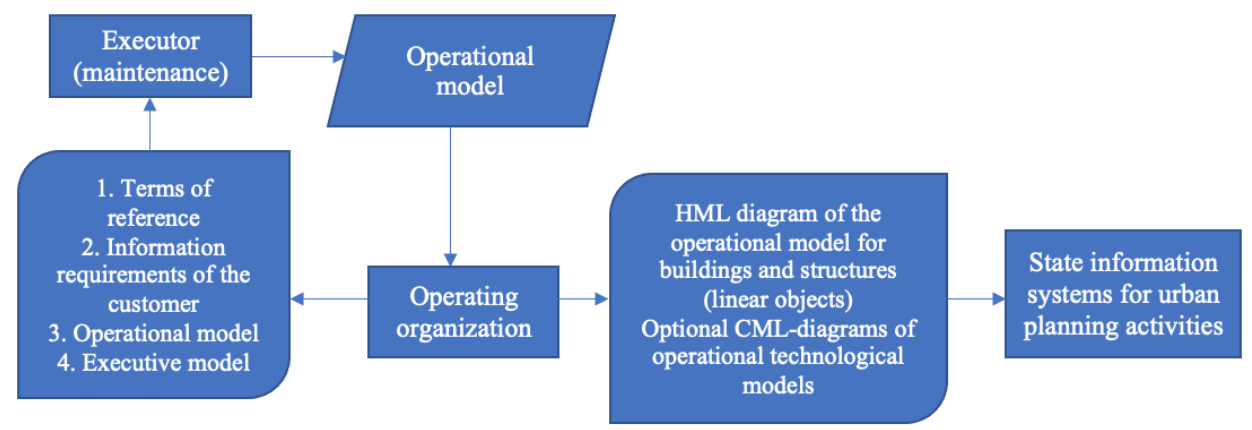

Fig. 5. Scheme of a scenario for using XML-schemes for the stage "Operation". 


\subsubsection{Stage "Demolition and disposal".}

The main participants in the demolition and disposal stage of the life cycle are:

- the developer, technical customer, the person responsible for the operation of the capital construction facility (hereinafter referred to as the customer);

- an individual entrepreneur or a legal entity performing work concluded with a developer, technical customer, a person responsible for the operation of a capital construction facility, under contracts for the demolition of capital construction facilities (hereinafter referred to as the contractor);

- the local government body of a settlement, urban district at the location of the capital construction object or, if the capital construction object is located in an inter-settlement territory, to the local government body of the municipal district (hereinafter - local government bodies);

- the body of state construction supervision.

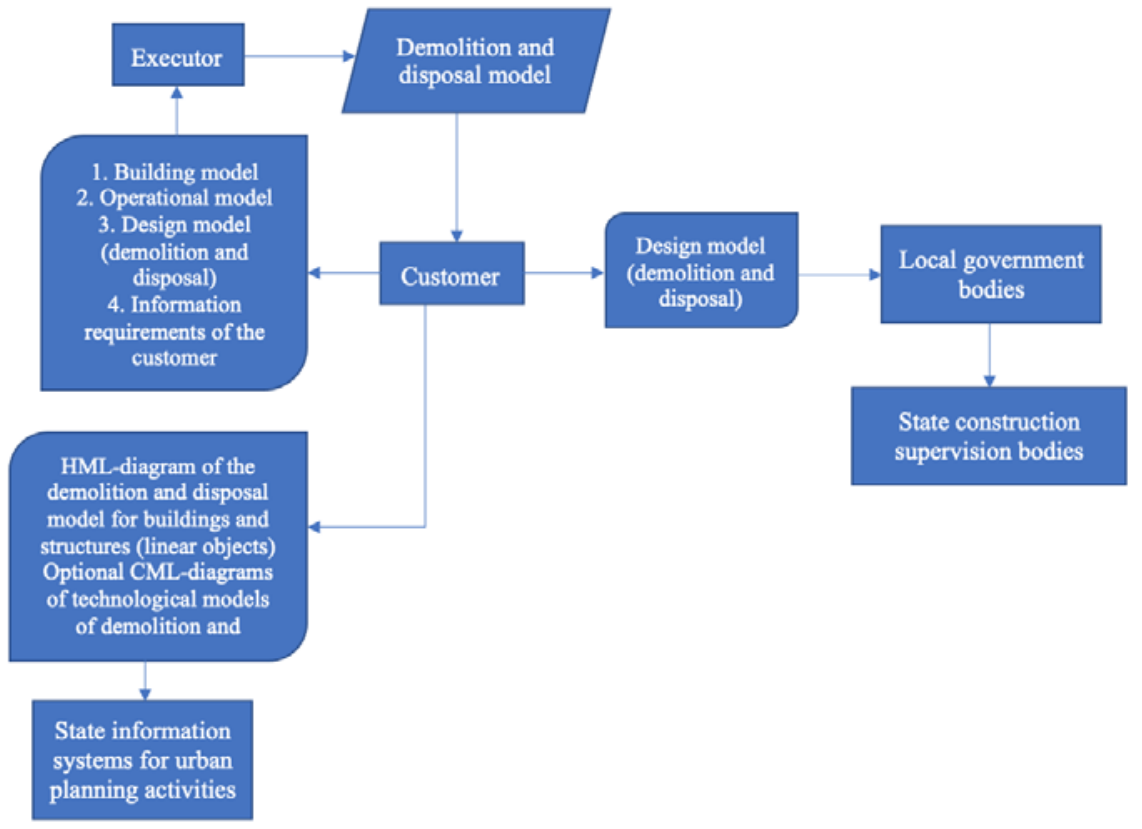

Fig. 6. Diagram of a scenario for using xml-schemes for the stage "Demolition and utilization".

The proposed scenario matrices are universal. When new participants or information systems are added to them, they can be transformed under new conditions without the involvement of significant resources.

\subsection{Requirements for $X M L$ schemas}

The introduction of digital technologies creates the preconditions for complex interaction and cooperation both between commercial organizations in the construction industry and between regulatory bodies on an international scale. A common language and data standards are vital for the consistent presentation of information, analysis, decision making and interpretation. The formation of common approaches will increase the regulator's ability to interact with other regulators, operators and third-party suppliers within a single information space. Data standards will help ensure transparency, consistency, and reliability 
of information. Data regulatory standards will reduce the complexity for operators and suppliers both nationally and internationally.

Based on the analysis of XML schemas of various professional organizations, such as BuildingSmart International, Public Petroleum Data Model Association, European Process Industries STEP Technical Liaison Executive, requirements for the structure of information transmitted during the implementation of various stages of an investment and construction project were formulated.

Requirements for the information transmitted during and after the project should be based on the use of this information by the business throughout the entire life cycle of the asset. Given the dynamics of the introduction and development of digital technologies in the construction industry, it is advisable to conduct regular studies to identify all types of activities at each stage of the asset life cycle, which should cover the development of feasibility studies, project planning, design, construction, normal operation, management of abnormal situations, maintenance and engineering work, as well as change management and government control. For each activity, the necessary engineering information should be defined (for each role and the definition of the corresponding rights and access rules). The information requirements for health and safety, safety, environmental protection and quality assurance should also be carefully reviewed. As a result of this study, there should be a business requirements specification that establishes the information requirements for information exchange.

A standard set of information requirements for asset management in an integrated information modeling framework contains the following data:

- Access to design information;

- Access to schematic drawings;

- Access to engineering drawings;

- Access to operating manuals;

- Access to information on maintenance;

- Access to information on spare parts;

- Maintenance workflow management;

- Hazardous Substances Management (including access to material safety data) spare parts and procurement management;

- Improved design and customization of work permissions and access management, including simulation;

- Process change management;

- New engineering developments and modifications;

- Accounting and distribution of products;

- Management of safety records;

- Management of equipment history and records of maintenance and preventive maintenance, as well as reports on production planning and production schedule;

- Operational monitoring and review.

It is important to note aspects of the classification of information based on its business value:

1. Not all information has the same business value. A systematic approach should be taken to classify information in order to apply an appropriate information management strategy based on the value of the information.

2. All information can be divided into dynamic or static information.

3. Dynamic information that can be updated to reflect the current state of, say, a plant is different from static information, where it cannot be updated at all. For example, an inspection report, once completed, should not be updated. In this case, only a new report can be generated. 
To ensure maximum compatibility with foreign approaches, it is proposed as a basis to use a scheme based on the open standard IFC 4.

As a result of the analysis of existing practice, taking into account the task at hand, it is planned that the XML schema will be managed by the RF Ministry of Construction. It is recommended that you use importing (<import>) XML schema information modeling, that is, use a design approach with a heterogeneous namespace.

It is not recommended to copy information model XML schema components into the project namespace for the following reasons:

- very quickly the local copy of the project is out of sync with other XML schemas, which will lead to the impossibility of automated validation of XML documents containing information model data;

- the ability to interoperate with applications that will process these and other XML schemas will be lost.

The following are some guidelines for developing XML schemas for information modeling:

1. A chameleon-type namespace is used:

- XML schemas that contain components that do not have inherited semantics by themselves;

- with XML schemas, which contain components that have semantics only in the context of the main XML schema;

- when you do not want to hard-code the namespace for the XML schema so that you can assign the projected components the specific namespace of the application in which they will be used.

2. A homogeneous namespace is used:

- if all XML schemas are conceptually related to each other;

- if there is no need to visually identify in the XML document that elements and attributes belong to a particular XML schema.

3. A heterogeneous namespace is used:

- when there are several elements with the same name (in order to prevent name collisions);

- if there is a need to visually identify in an XML document the belonging of elements and attributes to a particular XML schema.

\section{Discussion}

The concept of using XML schemas for the transfer and storage of information, documents and materials included in the information model of capital construction objects in the full life cycle includes a draft Roadmap for the development of a system for using XML schemas in state information systems for ensuring urban planning activities in 2021-2028. The draft roadmap includes 2 stages ( 2 planning horizons) - short and medium term.

The short-term planning horizon - until 2023, involves the development of a complete family of XML schemas required to support the life cycle of a capital construction project, taking into account:

- presentation of Digital Indormation Model (DIM) and Engineering Digital Terrain Model (EDTM) in the form of XML documents;

- submission of descriptions of other electronic documents as part of Information Model of capital construction object in the form of XML documents with the ability to attach scanned copies. 
The mid-term planning horizon - until 2028, involves the revision of the complete family of XML schemas required to support the life cycle of a capital construction project, taking into account:

- presentation of Digital Indormation Model (DIM) and Engineering Digital Terrain Model (EDTM) in the form of XML documents;

- presentation of other electronic documents as part of Information Model of capital construction object in the form of XML documents with the ability to integrate at the level of data exchange between various information systems.

\section{Conclusion}

Methodological approaches to the use of standard models for forming the structure of an information model at different stages of the life cycle for different types of capital construction objects contain universal schemas of scenarios for the use of XML schemas for various stages of the life cycle of a capital construction object.

Requirements for XML schemas, which fully define the structure and composition of the information model, are formulated in an amount sufficient for the development of XML schemas as part of further work. The formulated requirements are consistent with the requirements of the updated edition of the Code of Rules 333.1325800.2017 "Information modeling in construction. Rules for the formation of an information model of objects at different stages of the life cycle".

This work was financially supported by the Ministry of Science and Higher Education of the Russian Federation (\#BC-4555.2018.1).

\section{References}

1. The Town Planning Code of the Russian Federation dated December 29, 2004 No. 190-FL.

2. Federal Law of the Russian Federation "On Electronic Signature" dated 06.04.2011 No. 63-FL.

3. Federal Law of the Russian Federation "On Information, Information Technologies and Information Protection" dated July 27, 2006 No. 149-FL.

4. Federal Law of March 20, 2011 No. 41-FL "On the Federal State Information System for Territorial Planning".

5. Federal Law of 30.12.2015 No. 431-FL “On Geodesy, Cartography and Spatial Data”.

6. Order of the President of the Russian Federation dated May 18, 2017 No. 163-rp "Plan for the transition to the use of domestic geoinformation technologies".

7. Decree of the Government of the Russian Federation of March 26, 2019 No. 319 "On a unified information system for housing construction".

8. Decree of the Government of the Russian Federation of 08.06.2011 No. 451 "On the infrastructure providing information and technological interaction of information systems used to provide state and municipal services in electronic form".

9. Decree of the Government of the Russian Federation of 12.04.2012 No. 289 "On the federal state information system of territorial planning".

10. Decree of the Government of the Russian Federation dated 09.06.2006 No. 363 "On information support of urban planning activities".

11. Decree of the Government of the Russian Federation dated July 24, 2017 No. 878 "On 
the procedure for forming a unified state register of expert examination conclusions of design documentation for capital construction projects and amending the Resolution of the Government of the Russian Federation dated March 05, 2007 No. 145".

12. Decree of the Government of the Russian Federation dated 05.03.2007 No. 145 "On the procedure for organizing and conducting state expertise of project documentation and the results of engineering surveys".

13. Decree of the Government of the Russian Federation of 23.09.2016 No. 959 "On the federal information system of pricing in construction".

14. Resolution of the Government of the Russian Federation of April 21,2018 No.482 "On the state information system" Typical cloud solution for the automation of control (supervisory) activities".

15. Decree of the Government of the Russian Federation of 15.04.2014 No. 316 "On approval of the state program of the Russian Federation" Economic development and innovative economy".

16. Decree of the Government of the Russian Federation of 28.11.2011 No. 977 "On the federal state information system" A unified system of identification and authentication in the infrastructure that provides information technology interaction of information systems used to provide state and municipal services in electronic form. "

17. Decree of the Government of the Russian Federation of 10.07.2013 No. 584 "On the use of the federal state information system" A unified identification and authentication system in the infrastructure providing information and technological interaction of information systems used to provide state and municipal services in electronic form. "

18. Decree of the Government of the Russian Federation of January 19, 2006 No. 20 "On engineering surveys for the preparation of design documentation, construction, reconstruction of capital construction facilities".

19. Decree of the Government of the Russian Federation dated 16.02.2008 No. 87 "On the composition of sections of project documentation and requirements for their content".

20. Decree of the Government of the Russian Federation dated 01.02.2006 No. 54 "On state construction supervision in the Russian Federation". 